\title{
2,3-Diarylxanthones as strong scavengers of reactive oxygen and nitrogen species: A structure-activity relationship study
}

\author{
Clementina M. M. Santos ${ }^{\mathrm{a}, *}$, Marisa Freitas ${ }^{\mathrm{b}}$, Daniela Ribeiro ${ }^{\mathrm{b}}$, Ana Gomes ${ }^{\mathrm{b}}$, Artur M. S. Silva ${ }^{\mathrm{c}}$, \\ José A. S. Cavaleiro ${ }^{c}$, Eduarda Fernandes ${ }^{\mathrm{b}, *}$ \\ ${ }^{a}$ Departamento de Produção e Tecnologia Vegetal, Escola Superior Agrária de Bragança, 5301-855 Bragança, Portugal \\ ${ }^{\mathrm{b}}$ REQUIMTE, Departamento de Química, Faculdade de Farmácia, Universidade do Porto, Rua Aníbal Cunha, 164, 4099-030 Porto, Portugal

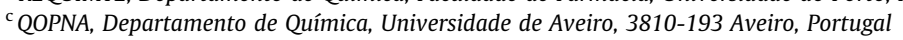

\begin{abstract}
A B S T R A C T
Xanthones are a class of oxygen-containing heterocyclic compounds widely distributed in nature. The natural derivatives can present different substitutions in the xanthone core that include hydroxyl, methoxyl, prenyl and glycosyl groups. The inclusion of aryl groups has only been reported for a few synthetic derivatives, the 2,3-diaryl moiety being recently introduced by our group. Xanthones are endowed with a broad spectrum of biological activities, many of them related to their antioxidant ability, including the scavenging of reactive oxygen species (ROS) and reactive nitrogen species (RNS), as well as metal chelating effects. Considering the interesting and promising antioxidant activities present in compounds derived from the xanthone core, the main goal of this work was to evaluate the scavenging activity of the new 2,3-diarylxanthones for ROS, including superoxide radical $\left(\mathrm{O}_{2}{ }^{--}\right)$, hydrogen peroxide $\left(\mathrm{H}_{2} \mathrm{O}_{2}\right)$, singlet oxygen $\left({ }^{1} \mathrm{O}_{2}\right)$, peroxyl radical (ROO-) and hypochlorous acid $(\mathrm{HOCl})$, and RNS, including nitric oxide ( $\mathrm{NO})$ and peroxynitrite anion $\left(\mathrm{ONOO}^{-}\right)$. The obtained results revealed that the tested 2,3-diarylxanthones are endowed with outstanding ROS and RNS scavenging properties, considering the nanomolar to micromolar range of the $\mathrm{IC}_{50}$ values found. The xanthones with two catechol rings were the most potent scavengers of all tested ROS and RNS. In conclusion, the new 2,3-diarylxanthones are promising molecules to be used for their potential antioxidant properties.
\end{abstract}

\section{Introduction}

Xanthones are a class of oxygen-containing heterocyclic compounds widely distributed in nature. ${ }^{1}$ They occur in two major plant families, Guttiferae and Gentianaceae and in some families of fungi and lichens. ${ }^{2,3}$ These natural derivatives can present different substitutions in the xanthone core that include hydroxyl, methoxyl, prenyl and glycosyl groups. ${ }^{4,5}$ The inclusion of aryl groups has only been reported for a few synthetic derivatives and the 2,3-diaryl moiety has never been presented before our synthetic work. ${ }^{6-10}$

The pharmacological properties of xanthones published in the last decades reveal the growing interest in this type of compounds. ${ }^{11}$ The pioneering work of Finnegan et al., ${ }^{12}$ in 1968, reported the diuretic action of mangiferin, a natural xanthone glycoside. Later on, Da Re et al. ${ }^{13}$ reported the analeptic activity of synthetic aminoalkylxanthone derivatives. Since then, the biological profiles of natural and even synthetic analogues have been

* Corresponding authors. Tel.: +351 222078968; fax: +351 222004427 (E.F.); tel.: +351 273303308; fax: +351 273325405 (C.M.M.S.).

E-mail addresses: clems@ipb.pt (C.M.M. Santos), egracas@ff.up.pt (E. Fernandes). extensively reported in the literature, namely anti-allergic, ${ }^{14,15}$ antifungal, ${ }^{16,17}$ anti-inflammatory, ${ }^{18,19}$ antimalarial, ${ }^{20,21}$ antitumour, ${ }^{22,23}$ hepatoprotective activity, ${ }^{24}$ inhibition of monoamine oxidase, ${ }^{25}$ and other enzymes, like cholinesterase ${ }^{26}$ and angiotensin I converting-enzyme. ${ }^{27}$ In this broad spectrum of biological activities special mention deserves also the antioxidant ${ }^{11}$ activity demonstrated by several xanthones. The antioxidant properties have been exemplified by their action as free radical scavengers, inhibitors of lipid peroxidation and as metal chelators. ${ }^{11,28,29}$

The recognized participation of reactive oxygen species (ROS) and reactive nitrogen species (RNS) in several physiopathologies and in cellular signalling systems has attracted growing interest from the health sector over the last few decades. In addition, the quest for effective antioxidants for food, cosmetic and pharmaceutical purposes has become a major industrial and scientific research challenge. Considering the interesting and promising studies already performed in xanthones, concerning their antioxidant activities, the development of new and effective scavengers of ROS and RNS using a xanthone scaffold seems therefore to be an interesting approach in this area. Thus, the main goal of this work was to evaluate the scavenging activity of the new synthetic 2,3-diarylxanthones derivatives for ROS, such as superoxide radical 
$\left(\mathrm{O}_{2} \cdot{ }^{-}\right)$, hydrogen peroxide $\left(\mathrm{H}_{2} \mathrm{O}_{2}\right)$, singlet oxygen $\left({ }^{1} \mathrm{O}_{2}\right)$, peroxyl radical (ROO-) and hypochlorous acid ( $\mathrm{HOCl})$, and RNS, such as nitric oxide ('NO) and peroxynitrite anion $\left(\mathrm{ONOO}^{-}\right)$(Fig. 1).

\section{Results}

\subsection{Superoxide radical scavenging activity}

Only 2,3-diarylxanthones 3a-c could prevent the $\mathrm{O}_{2}{ }^{--}$-dependent reduction of NBT in a concentration-dependent manner (Table 1). Compound $\mathbf{3 c}$ was considerably the most efficient, of this group and of all the tested compounds, presenting an $\mathrm{IC}_{50}$ of $10.4 \pm 0.8 \mu \mathrm{M}$. Compounds $2 \mathbf{c}, 1 \mathrm{c}$ and $\mathbf{3 b}$ are also potent scavengers, providing $\mathrm{IC}_{50} \mathrm{~S}$ of $20.3 \pm 2.5,28.1 \pm 2.3$ and $31.3 \pm 3.2 \mu \mathrm{M}$, respectively.

2,3-Diarylxanthones 1a, $1 \mathbf{b}$ and $\mathbf{2 a}$ were completely ineffective up to the highest tested concentration (compound 1a, $25 \mu \mathrm{M}$ and compounds $\mathbf{1 b}$ and $\mathbf{2 a}, 200 \mu \mathrm{M}$ ).

The $\mathrm{IC}_{50}$ values presented in Table 1 for $\mathrm{O}_{2}{ }^{-}$- scavenging activity vary from 10.4 to $166 \mu \mathrm{M}$ (compound $\mathbf{2 b}$ ) and are significantly lower than the $\mathrm{IC}_{50}$ value found for the positive control, tiron $\left(\mathrm{IC}_{50}=273 \pm 32 \mu \mathrm{M}\right)$.

\subsection{Hydrogen peroxide scavenging activity}

The results presented in Table 1 refer only to the $\mathrm{H}_{2} \mathrm{O}_{2}$ scavenging activity of the tested 2,3-diarylxanthones in a range of $125-250 \mu \mathrm{M}$, due to the precipitation that occurred in the sample wells at higher concentrations.

Vestigial scavenging activity was observed for xanthones 3a-c. Compounds $\mathbf{3 b}$ and $\mathbf{3 c}$ caused $17 \%$ and $12 \%$ inhibition of chemiluminescence, respectively, at their maximum concentration $(250 \mu \mathrm{M})$. From $\mathbf{2 a}-\mathbf{c}$, only $\mathbf{2 c}$ presented a slight effect of $14 \%$ at the highest tested concentration $(250 \mu \mathrm{M})$. The derivatives 3a and 1c presented similar effects and did not reach $10 \%$ effect at the maximum tested concentration $(125 \mu \mathrm{M})$.

No scavenging activity was found for 2,3-diarylxanthones $\mathbf{1 a , b}$ and $\mathbf{2 a}, \mathbf{b}$, at concentrations up to $125 \mu \mathrm{M}$.

The positive control, ascorbic acid, provided an $\mathrm{IC}_{50}$ of $602 \pm 80 \mu \mathrm{M}$.

\subsection{Hypochlorous acid scavenging activity}

All the tested compounds were able to scavenge $\mathrm{HOCl}$ in a concentration-dependent manner. The $\mathrm{HOCl}$-induced oxidation of dihydrorhodamine 123 (DHR) was efficiently prevented by hydroxy-2,3-diarylxanthones $\mathbf{3 a}-\mathbf{c}$, being $\mathbf{3} \mathbf{c}$ and $\mathbf{3 b}$ the most effective derivatives, providing $\mathrm{IC}_{50}$ values of $1.2 \pm 0.02$ and $7.5 \pm 0.7 \mu \mathrm{M}$, respectively (Table 1 ).

From compounds $\mathbf{1 a}-\mathbf{c}$ and $\mathbf{2 a - c}, 1 \mathrm{c}$ and $\mathbf{2 c}$ proved to be the most active ones $\left(\mathrm{IC}_{50}=15.7 \pm 1.1\right.$ and $14.7 \pm 1.3 \mu \mathrm{M}$, respectively). However, the $\mathrm{IC}_{50}$ values were slightly higher than the obtained for the compound $3 \mathrm{a}\left(\mathrm{IC}_{50}=10.8 \pm 0.4 \mu \mathrm{M}\right)$.
Table 1

$\mathrm{O}_{2} \cdot-, \mathrm{H}_{2} \mathrm{O}_{2},{ }^{1} \mathrm{O}_{2}$ and $\mathrm{HOCl}$ scavenging activity $\left(\mathrm{IC}_{50}\right.$, mean \pm SEM) and ROO- scavenging activity (concentration range $0.125-1.0 \mu \mathrm{M}$ ) expressed as ORAC values (mean \pm SEM) of the tested 2,3-diarylxanthones and positive controls

\begin{tabular}{|c|c|c|c|c|c|}
\hline \multirow[t]{2}{*}{ Compound } & \multicolumn{4}{|c|}{$\mathrm{IC}_{50}(\mu \mathrm{M})$} & \multirow{2}{*}{$\begin{array}{l}\mathrm{ORAC}_{\mathrm{ROO}} \pm \mathrm{SEM} \\
(\mu \mathrm{M} \text { trolox equiv/ } \\
\mu \mathrm{M} \text { compound) }\end{array}$} \\
\hline & $\mathrm{O}_{2} \cdot-$ & $\mathrm{H}_{2} \mathrm{O}_{2}$ & $\mathrm{HOCl}$ & ${ }^{1} \mathrm{O}_{2}$ & \\
\hline \multicolumn{6}{|c|}{ 2,3-Diarylxanthones } \\
\hline 1a & $\mathrm{NA}^{25 \mu \mathrm{M}}$ & $\mathrm{NA}^{125 \mu \mathrm{M}}$ & $155 \pm 25$ & $27 \%^{*} 100 \mu \mathrm{M}$ & $\mathrm{NA}^{1 \mu \mathrm{M}}$ \\
\hline 1b & $\mathrm{NA}^{200 \mu \mathrm{M}}$ & $\mathrm{NA}^{125 \mu \mathrm{M}}$ & $72.1 \pm 8.6$ & $80 \pm 11$ & $1.05 \pm 0.09$ \\
\hline 1c & $28.1 \pm 2.3$ & $9 \%{ }^{* 125 \mu \mathrm{M}}$ & $15.7 \pm 1.1$ & $6.0 \pm 1.0$ & $0.76 \pm 0.01$ \\
\hline $\mathbf{2 a}$ & $\mathrm{NA}^{200 \mu \mathrm{M}}$ & $\mathrm{NA}^{125 \mu \mathrm{M}}$ & $53.8 \pm 7.8$ & $68.8 \pm 6.2$ & $2.08 \pm 0.16$ \\
\hline 2b & $166 \pm 16$ & $\mathrm{NA}^{125 \mu \mathrm{M}}$ & $22.4 \pm 2.5$ & $58.4 \pm 4.9$ & $2.88 \pm 0.09$ \\
\hline $2 c$ & $20.3 \pm 2.5$ & $14 \%^{* 250 \mu \mathrm{M}}$ & $14.7 \pm 1.3$ & $3.3 \pm 0.7$ & $0.88 \pm 0.12$ \\
\hline $3 a$ & $76 \pm 11$ & $9 \%{ }^{* 125 \mu \mathrm{M}}$ & $10.8 \pm 0.4$ & $4.5 \pm 0.6$ & $0.84 \pm 0.01$ \\
\hline 3b & $31.3 \pm 3.2$ & $12 \%^{* 250 \mu \mathrm{M}}$ & $7.5 \pm 0.7$ & $6.8 \pm 0.5$ & $0.83 \pm 0.03$ \\
\hline $3 c$ & $10.4 \pm 0.8$ & $17 \% \%^{* 250 \mu \mathrm{M}}$ & $1.2 \pm 0.02$ & $2.5 \pm 0.2$ & $0.28 \pm 0.03$ \\
\hline \multicolumn{6}{|c|}{ Positive controls } \\
\hline Tiron & $273 \pm 32$ & - & - & - & - \\
\hline Ascorbic acid & - & $602 \pm 80$ & - & - & $0.22 \pm 0.03$ \\
\hline $\begin{array}{l}\text { Dihydrolipoic } \\
\text { acid }\end{array}$ & - & - & $2.3 \pm 0.3$ & - & - \\
\hline Quercetin & - & - & - & $1.8 \pm 0.1$ & - \\
\hline
\end{tabular}

NA: no activity was found up to the highest tested concentration (in superscript)

Scavenging effect (mean\%) at the highest tested concentration (in superscript).

It was possible to determine the $\mathrm{IC}_{50}$ of 2,3-diarylxanthone $\mathbf{1 a}$, along the studied concentration range $(25-200 \mu \mathrm{M})$ at $155 \pm 25 \mu \mathrm{M}$.

The $\mathrm{IC}_{50}$ of the positive control dihydrolipoic acid was $2.3 \pm 0.3 \mu \mathrm{M}$.

\subsection{Singlet oxygen scavenging activity}

The 2,3-diarylxanthones proved to be effective scavengers of ${ }^{1} \mathrm{O}_{2}$ in a concentration-dependent manner, except for compound 1a, which only reached $27 \%$ effect at the highest tested concentration $(100 \mu \mathrm{M})$ (Table 1$)$. For compounds 1a-c, 1c $\left(\mathrm{IC}_{50}=6.0 \pm 1.0\right.$ $\mu \mathrm{M})$ was noticeably more active than compound $\mathbf{1 b}\left(\mathrm{IC}_{50}=80 \pm\right.$ $11 \mu \mathrm{M})$.

For compounds $2 \mathbf{2 a - c , 2 c}$ was the most potent $\left(\mathrm{IC}_{50}=3.3 \pm\right.$ $0.7 \mu \mathrm{M})$ and the obtained $\mathrm{IC}_{50}$ for $\mathbf{2 b}\left(\mathrm{IC}_{50}=58.4 \pm 4.9 \mu \mathrm{M}\right)$ was slightly lower than that of $\mathbf{2 a}\left(\mathrm{IC}_{50}=68.8 \pm 6.2 \mu \mathrm{M}\right)$.

2,3-Diarylxanthones $\mathbf{3 a - c}$ revealed to be very active compounds, the scavenging activity order being $\mathbf{3} \mathbf{c}>\mathbf{3} \mathbf{a}>\mathbf{3 b}$, with $\mathrm{IC}_{50} \mathrm{~S}$ of $2.5 \pm 0.2,4.5 \pm 0.6$ and $6.8 \pm 0.5 \mu \mathrm{M}$, respectively.

Quercetin (positive control) efficiently scavenge ${ }^{1} \mathrm{O}_{2}$ $\left(\mathrm{IC}_{50}=1.8 \pm 0.1 \mu \mathrm{M}\right)$.

\subsection{Peroxyl radical scavenging activity}

As seen in Table 1, all the assayed compounds, except 1a, were able to delay the loss of fluorescence, due to ROO-dependent fluorescein oxidation, in a concentration-dependent way. Compound 1a did not show any scavenging activity along the studied concen-

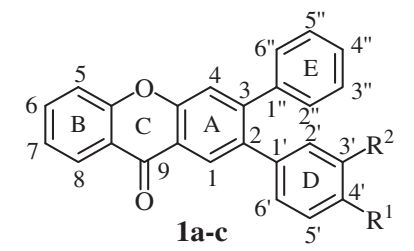

a) $\mathrm{R}^{1}=\mathrm{R}^{2}=\mathrm{H}$

b) $\mathrm{R}^{1}=\mathrm{OH}, \mathrm{R}^{2}=\mathrm{H}$

c) $\mathrm{R}^{1}=\mathrm{R}^{2}=\mathrm{OH}$<smiles>[R]c1ccc(-c2cc3c(=O)c4ccccc4oc3cc2-c2ccc(O)cc2)cc1[R]</smiles>

a) $\mathrm{R}^{1}=\mathrm{R}^{2}=\mathrm{H}$

b) $\mathrm{R}^{1}=\mathrm{OH}, \mathrm{R}^{2}=\mathrm{H}$

c) $\mathrm{R}^{1}=\mathrm{R}^{2}=\mathrm{OH}$<smiles>[Y]c1ccc(-c2cc3c(=O)c4ccccc4oc3cc2-c2ccc(O)c(O)c2)cc1[Y]</smiles>

a) $\mathrm{R}^{1}=\mathrm{R}^{2}=\mathrm{H}$

b) $\mathrm{R}^{1}=\mathrm{OH}, \mathrm{R}^{2}=\mathrm{H}$

c) $\mathrm{R}^{1}=\mathrm{R}^{2}=\mathrm{OH}$

Figure 1. Chemical structures of the studied 2,3-diarylxanthones. 
tration range (0.125-1 $\mu \mathrm{M})$ and the other tested compounds were considerably more active than the endogenous antioxidant, ascorbic acid, which presented an ORAC (oxygen radical absorbance capacity) value of $0.22 \pm 0.03 \mu \mathrm{M}$.

2,3-Diarylxanthones $\mathbf{1 b}, 2 \mathrm{a}$ and $\mathbf{2 b}$ were the most powerful scavengers of ROO; providing ORAC values of $1.05 \pm 0.09$, $2.08 \pm 0.16$ and $2.88 \pm 0.09 \mu \mathrm{M}$, respectively.

In contrast, compounds $\mathbf{3 a - c}$ along with compound $\mathbf{1 c}$ were the less active ones, presenting ORAC values from 0.28 to $0.84 \mu \mathrm{M}$.

\subsection{Nitric oxide scavenging activity}

All the tested compounds were able to scavenge $\mathrm{NO}$-induced oxidation of 4,5-diaminofluorescein (DAF-2) in a concentrationdependent manner (Table 2).

Compounds $\mathbf{2 c}$ and $\mathbf{3 c}$ were the most effective ones, presenting a very similar activity with $\mathrm{IC}_{50}$ rounding $0.4 \mu \mathrm{M}$, followed by $1 \mathrm{c}$, $\mathbf{3 a}$ and $\mathbf{3 b}$. The order of potencies found for these derivatives was: $\mathbf{3 c}>\mathbf{2 c}>\mathbf{3 b}>\mathbf{3 a}>\mathbf{1 c}$.

2,3-Diarylxanthones $\mathbf{1 b}$ and $\mathbf{2 b}$ revealed to be less potent and provided $\mathrm{IC}_{50} \mathrm{~S}$ of $175 \pm 36$ and $108 \pm 18 \mu \mathrm{M}$, respectively. Xanthones 1a and 2a presented only a slight effect of $39 \%$ and $41 \%$, respectively, at the maximum tested concentration $(200 \mu \mathrm{M})$.

The $\mathrm{IC}_{50}$ obtained for the flavonoid rutin (positive control) was $2.53 \pm 0.37 \mu \mathrm{M}$.

\subsection{Peroxynitrite scavenging activity}

The 2,3-diarylxanthones tested were shown to efficiently inhibit $\mathrm{ONOO}^{-}$-induced oxidation of DHR, in a concentration-dependent manner. However, the concentration-effect relationship on scavenging activity was different in the absence or in the presence of $25 \mathrm{mM} \mathrm{NaHCO}$. Generally, the compounds were shown to be more effective in the absence of $\mathrm{NaHCO}_{3}$ than in its presence, with the exception of compounds $\mathbf{2 a}$ and $\mathbf{2} \mathbf{b}$.

Compound $3 c$ proved to be the most active derivative, with $\mathrm{IC}_{50} \mathrm{~S}$ of $0.17 \pm 0.01$ and $0.33 \pm 0.06 \mu \mathrm{M}$, in the absence and in the presence of $\mathrm{NaHCO}_{3}$, respectively (Table 2).

Concerning other results in the absence of $\mathrm{NaHCO}_{3}$, compounds 2c and 3b $\left(\mathrm{IC}_{50}=0.26 \pm 0.05\right.$ and $0.22 \pm 0.03 \mu \mathrm{M}$, respectively) were visibly more efficient than compounds $\mathbf{1 c}$ and $\mathbf{3 a}$ $\left(\mathrm{IC}_{50}=0.40 \pm 0.03\right.$ and $0.37 \pm 0.09 \mu \mathrm{M}$, respectively). However, in the presence of $\mathrm{NaHCO}_{3}$, the relative order of potencies for these compounds is the opposite. The scavenging activity order was: 1c

$>\mathbf{3 a}>\mathbf{2 c}>\mathbf{3 b}$, with $\mathrm{IC}_{50}$ values of $0.54 \pm 0.08,0.67 \pm 0.09$ $0.78 \pm 0.26$ and $0.89 \pm 0.18 \mu \mathrm{M}$, respectively.

Table 2

'NO and $\mathrm{ONOO}^{-}$(with and without $25 \mathrm{mM} \mathrm{NaHCO}$ ) scavenging effects ( $\mathrm{IC}_{50}$, mean \pm SEM) of the tested 2,3-diarylxanthones and positive controls

\begin{tabular}{|c|c|c|c|}
\hline \multirow[t]{2}{*}{ Compound } & \multicolumn{3}{|c|}{$\mathrm{IC}_{50}(\mu \mathrm{M})$} \\
\hline & $\cdot \mathrm{NO}$ & $\mathrm{ONOO}^{-}$without $\mathrm{NaHCO}_{3}$ & $\mathrm{ONOO}^{-}$with $\mathrm{NaHCO}_{3}$ \\
\hline \multicolumn{4}{|c|}{ 2,3-Diarylxanthones } \\
\hline 1a & $39 \%^{* 200 \mu \mathrm{M}}$ & $29 \%{ }^{* 50 \mu \mathrm{M}}$ & $48 \%{ }^{* 50 \mu \mathrm{M}}$ \\
\hline 1b & $175 \pm 36$ & $1.55 \pm 0.14$ & $1.80 \pm 0.39$ \\
\hline 1c & $1.88 \pm 0.18$ & $0.40 \pm 0.03$ & $0.54 \pm 0.08$ \\
\hline $2 a$ & $41 \%^{* 200 \mu \mathrm{M}}$ & $2.66 \pm 0.29$ & $2.00 \pm 0.15$ \\
\hline 2b & $108 \pm 18$ & $1.72 \pm 0.21$ & $0.97 \pm 0.25$ \\
\hline 2c & $0.42 \pm 0.05$ & $0.26 \pm 0.05$ & $0.78 \pm 0.26$ \\
\hline 3a & $1.22 \pm 0.21$ & $0.37 \pm 0.09$ & $0.67 \pm 0.09$ \\
\hline 3b & $0.62 \pm 0.10$ & $0.22 \pm 0.03$ & $0.89 \pm 0.18$ \\
\hline $3 c$ & $0.39 \pm 0.05$ & $0.17 \pm 0.01$ & $0.33 \pm 0.06$ \\
\hline \multicolumn{4}{|c|}{ Positive controls } \\
\hline Rutin & $2.53 \pm 0.37$ & - & - \\
\hline Ebselen & - & $0.50 \pm 0.03$ & $2.01 \pm 0.22$ \\
\hline
\end{tabular}

Scavenging effect (mean\%) at the highest tested concentration (in superscript).
Similar results were obtained for compounds $\mathbf{1 b}$ and $\mathbf{2 b}$, being the former more efficient in the absence of $\mathrm{NaHCO}_{3}$ and the latest more effective in the presence of this salt.

Compound 1a was also able to scavenge $\mathrm{ONOO}^{-}$although its effect could only reach $29 \%$ and $48 \%$, at the maximum concentration tested $(50 \mu \mathrm{M})$, in the absence or in the presence of $\mathrm{NaHCO}_{3}$, respectively.

Ebselen, a well known $\mathrm{ONOO}^{-}$scavenger, presented an $\mathrm{IC}_{50}$ of $0.50 \pm 0.03 \mu \mathrm{M}$ in the absence of $\mathrm{NaHCO}_{3}$ and $2.01 \pm 0.22 \mu \mathrm{M}$ in its presence.

\section{Discussion}

The present study indicates that the tested 2,3-diarylxanthones 1-3 are promising molecules to be used for their potential antioxidant properties. The scavenging activity for ROS/RNS of these xanthone derivatives is reported for the first time, with outstanding results, considering the nanomolar to micromolar range of the $\mathrm{IC}_{50}$ values found. In our first approach, $\mathrm{O}_{2}^{--}$scavenging activity was assayed using a non enzymatic ( $\mathrm{NADH} /$ phenazine methosulfate) generating system. The results seem to be largely affected by the number and position of hydroxyl groups in $\mathrm{D}$ and $\mathrm{E}$ rings of the xanthone core. Several authors had already referred the importance of structure-activity relationship for the ability of several hydroxyxanthones to scavenge $\mathrm{O}_{2} \cdot-$, using different methodologies. ${ }^{30-32}$ Compound $\mathbf{3 c}$, bearing four hydroxyl groups, is the most effective scavenger of $\mathrm{O}_{2}^{-}$- (Fig. 2) followed by compounds $\mathbf{3} \mathbf{b}$ and 2c, which possess 3 hydroxyl groups. In this case, the scavenging activity of compound $\mathbf{2 c}$ is slightly higher than compound $\mathbf{3 b}$, suggesting that the presence of a catechol group in D-ring is more relevant than the presence of a catechol group in E-ring. The same effect was observed in compounds 1c and 3a, possessing an ortho-dihydroxyl substitution in D-ring and E-ring, respectively. Compound 2b that contains two hydroxyl groups, but no catechol moiety, was noticeably less potent than the compounds described before; the remaining phenol derivatives showed no activity.

Poor $\mathrm{H}_{2} \mathrm{O}_{2}$ scavenging activity was observed for all the tested compounds. However, it was not possible to test beyond the concentration of $250 \mu \mathrm{M}$ due to the low solubility of 2,3-diarylxanthones 1-3 in the tested system. Nevertheless, the scavenging values of derivatives $\mathbf{2 c}$, $3 \mathbf{b}$ and $\mathbf{3 c}(12-17 \%$ at a $250 \mu \mathrm{M}$ concentration) also suggest that the number and the position of hydroxyl groups are responsible for the $\mathrm{H}_{2} \mathrm{O}_{2}$-scavenging effects (Table 1). This hypothesis is only partially confirmed in the literature. Sun et al. ${ }^{30}$ monitored the $\mathrm{H}_{2} \mathrm{O}_{2}$-induced oxidation of luminol (a similar methodology to the described in this paper) and showed that $\alpha$-mangostin (a trihydroxyxanthone) presented evident inhibitory effect on $\mathrm{H}_{2} \mathrm{O}_{2}$ when compared with $\gamma$-mangostin (a dihydroxyxanthone). On the other hand, Pedraza-Chaverrí et al., ${ }^{33}$ using a different procedure, showed that $\alpha$-mangostin was unable to scavenge $\mathrm{H}_{2} \mathrm{O}_{2}$. From the analysis of our results, the tetrahydroxy-2,3diarylxanthone $\mathbf{3 c}$ is more active than the trihydroxyxanthones, $\mathbf{2 c}$ and $\mathbf{3 b}$. Therefore comparing the results of both trihydroxyxanthones one can conclude that the presence of a catechol unit in the D-ring of compound $\mathbf{2 c}$ can contribute for their slight higher effect relatively to the corresponding isomer $\mathbf{3 b}$.

The $\mathrm{HOCl}$-induced oxidation of DHR was efficiently prevented by all the tested 2,3-diarylxanthones. The results from the $\mathrm{HOCl}-$ scavenging assay show, once again, the importance of the orthodihydroxyl substitution for the antioxidant activity of 2,3-diarylxanthones (Fig. 3). In addition, the number of the hydroxyl groups also seems to contribute to the scavenging effect of these compounds. Indeed, compound $\mathbf{2} \mathbf{b}$, possessing two hydroxyl groups but not a catechol moiety, presents almost $100 \%$ inhibition of $\mathrm{HOCl}$-induced oxidation at a concentration of $100 \mu \mathrm{M}$. For lower concentrations, the scavenging activity of the tested xanthones 


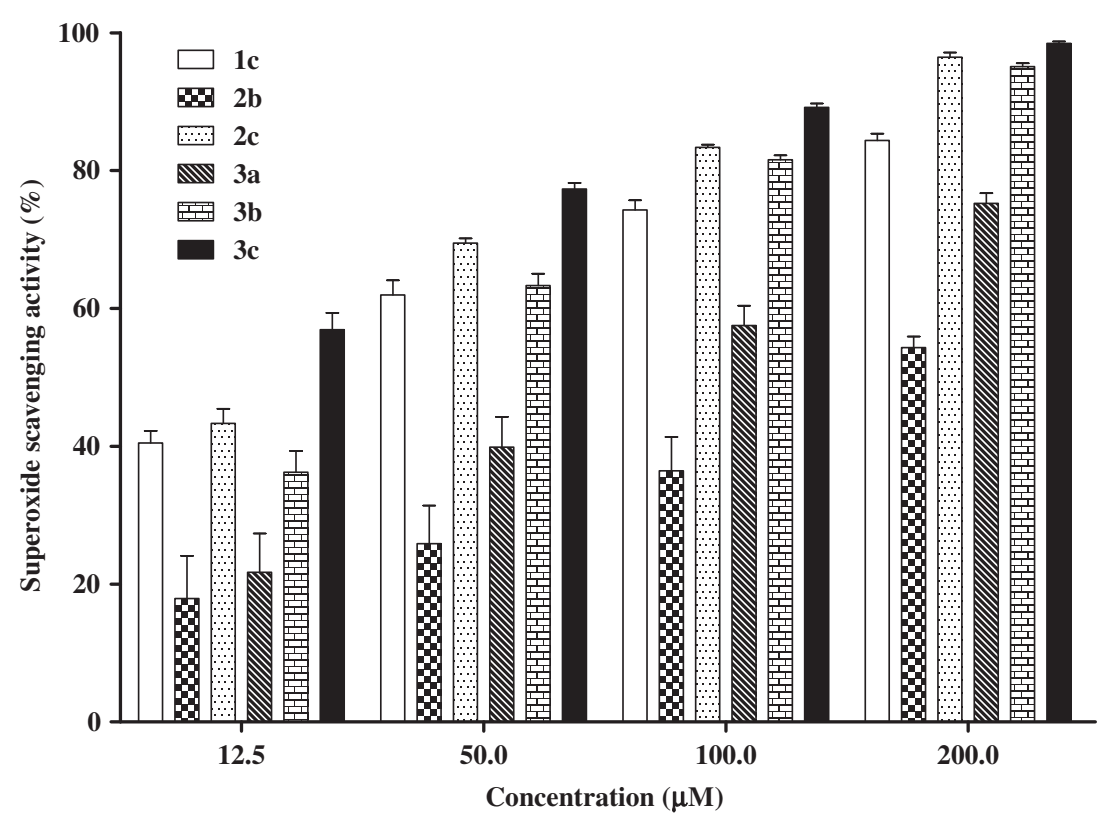

Figure 2. $\mathrm{O}_{2}^{--}$scavenging activity of 2,3-diarylxanthones 1c, 2b-3c. Each column represents the values obtained from five experiments, performed in triplicate (mean \pm SEM).

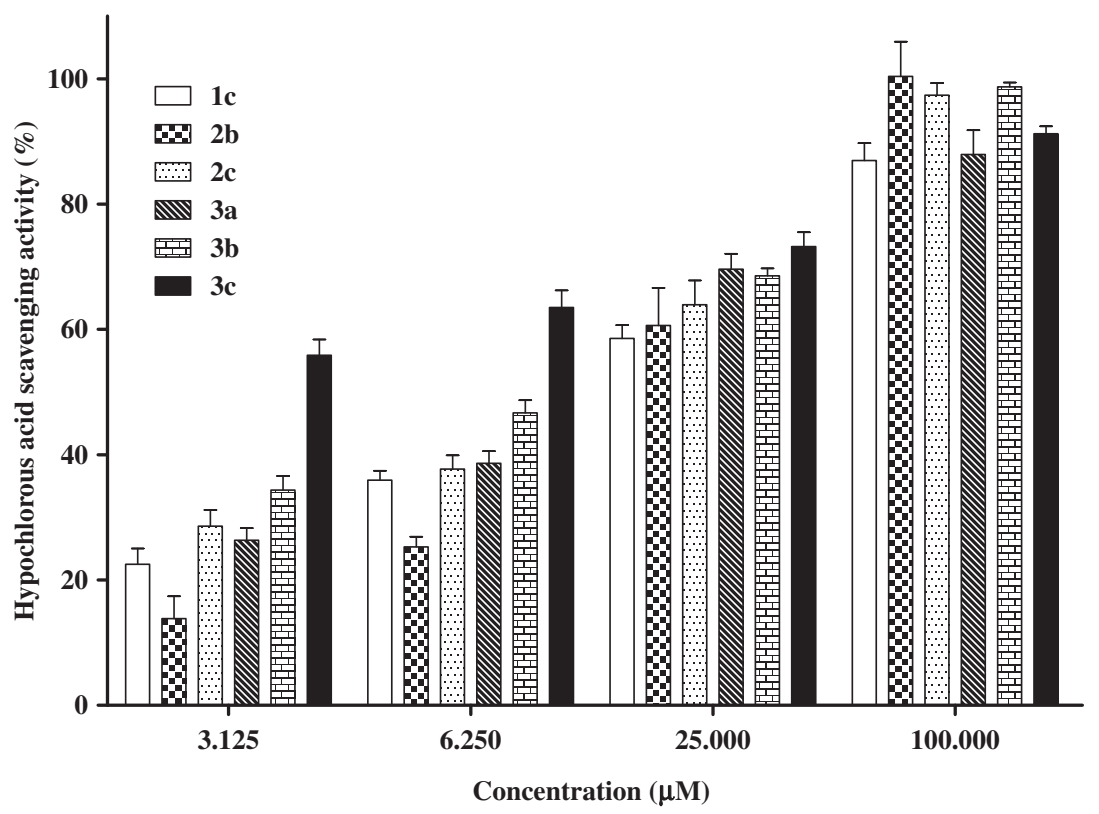

Figure 3. HOCl scavenging activity of 2,3-diarylxanthones 1c, 2b-3c. Each column represents the values obtained from five experiments, performed in triplicate (mean \pm SEM)

was visibly more affected by the presence of the catechol group rather than the number of hydroxyl substituents. This is clear by the analysis of the results, which shows that derivatives $3 a-c$ in addition of compounds $\mathbf{1 c}$ and $\mathbf{2 c}$ were all more effective scavengers than compound $\mathbf{2 b}$, at 6.25 and $3.125 \mu \mathrm{M}$ concentration (Fig. 3).

In agreement with the results from other ROS, the ${ }^{1} \mathrm{O}_{2}$ scavenging activity of 2,3-diarylxanthones depends particularly on the $\mathrm{OH}$ substitution pattern. Compounds with a catechol unit presented a considerably higher effect than those lacking this feature as it can be confirmed by the $\mathrm{IC}_{50}$ values. 2,3-Diarylxanthones $\mathbf{1 c}, \mathbf{2 c}$, 3a-c presented $\mathrm{IC}_{50}$ values in a range of $2.5-6.8 \mu \mathrm{M}$ and compounds $\mathbf{1 b}, \mathbf{2 a}, \mathbf{b}$, having a phenol instead of a catechol ring, were noticeably less potent, with $\mathrm{IC}_{50} \mathrm{~S}$ rounding $58.4-80 \mu \mathrm{M}$ (Table 1 ).
Other interesting feature could be suggested by the analysis of Figure 4 , which presents the results of the ${ }^{1} \mathrm{O}_{2}$ scavenging activity of 2,3-diarylxanthones possessing at least a catechol unit. We can observe that, for concentrations of $10-20 \mu \mathrm{M}$, the presence of two catechol groups in compound $\mathbf{3 c}$ seems to be essential for the high scavenging potential of this derivative. In contrast, for the lower concentrations, the number of catechol units does not seem to bring any advantage to the scavenging activity, all the derivatives presenting similar effects.

The data presented in Table 1 show that all the hydroxyxanthones tested provided higher ORAC values than the endogenous antioxidant ascorbic acid. The ROO scavenging activity of these compounds seems to mostly depend on the hydroxylation pattern 


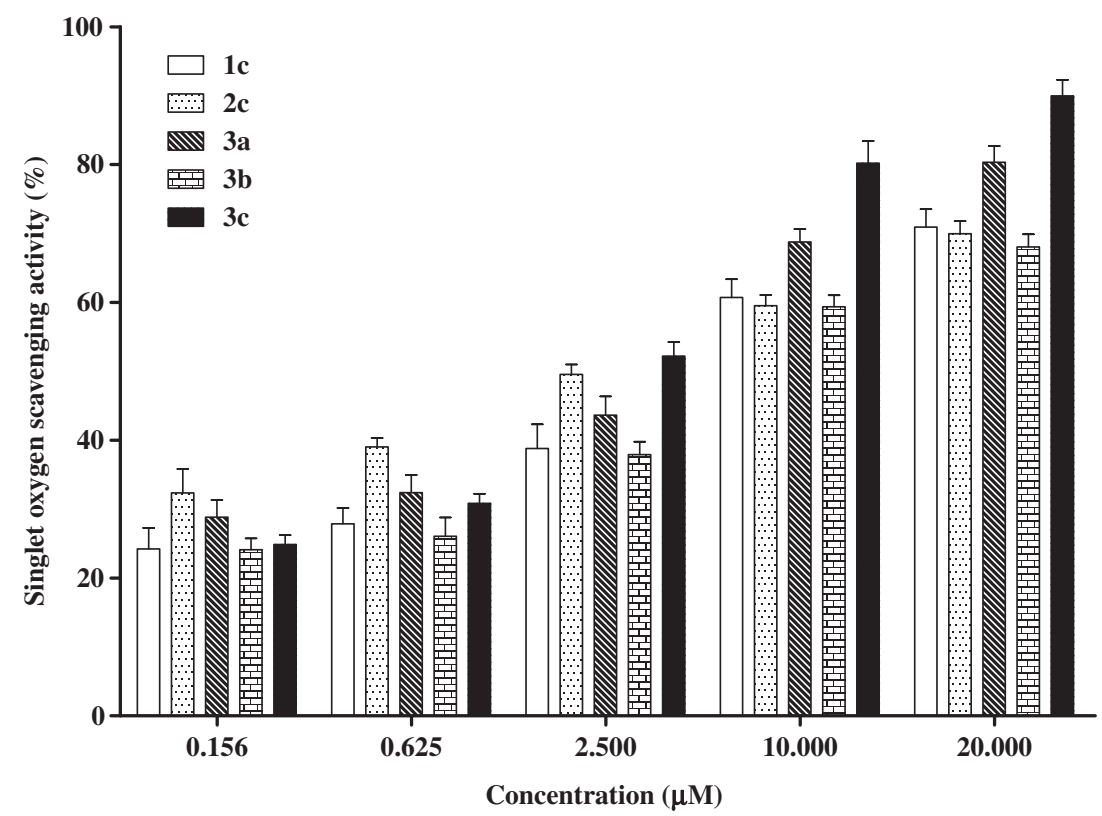

Figure 4. ${ }^{1} \mathrm{O}_{2}$ scavenging activity of 2,3-diarylxanthones $\mathbf{1 c}, \mathbf{2 c}$, 3a-c. Each column represents the values obtained from five experiments, performed in triplicate $($ mean \pm SEM).

in the aryl groups. However, in this assay, the presence of phenol groups seems to be extremely important for the scavenging effect. The highest ORAC value was obtained for compound $\mathbf{2 b}$, a xanthone bearing two phenol groups as substituents. The introduction of an additional $\mathrm{OH}$ substituent drastically decreases the scavenging activity as it is evident by the results of compounds $\mathbf{3 a - c}$. 2,3-Diarylxanthone 3c, a derivative with two ortho-dihydroxyl groups, provided the lowest ORAC value from all the tested hydroxyxanthone. These observations are not in accordance to the knowledge about structure-activity relationship of flavonoids and phenolic compounds. The ortho-dihydroxyl substitution is particularly important to the ROO absorbing activity of those classes of compounds. ${ }^{34-36}$ The mechanism involves the $\mathrm{H}$-atom donating ability of the antioxidant to the ROO; thus acting as chain radical terminator.

The $\mathrm{NO}$ scavenging activity indicates that the $\mathrm{OH}$-substitution pattern in the aryl groups is the main factor responsible for the scavenging effect of this RNS. The compounds with a catechol group play an important role as protectors of the $\mathrm{NO}$-dependent oxidation of DAF-2 (Fig. 5). Yet, this group of compounds is also much more effective than rutin, a flavonoid, which is a well-known 'NO scavenger. The other 2,3-diarylxanthones provided a much weaker effect, as can be confirmed by the analysis of the results presented in Table 2.

Some of us had already studied the NO scavenging activity of some flavones and 2-styrylchromones. ${ }^{37,38}$ In general, the

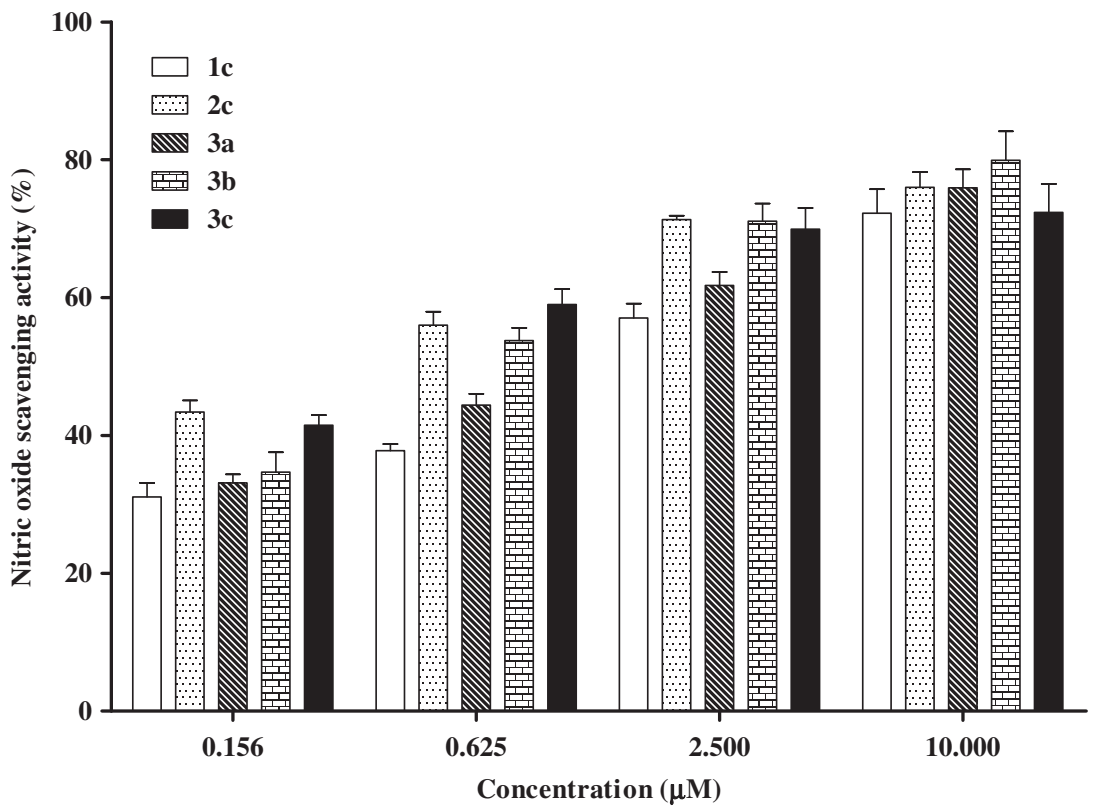

Figure 5. NO scavenging activity of 2,3-diarylxanthones 1c, 2c, 3a-c. Each column represents the values obtained from five experiments, performed in triplicate (mean \pm SEM). 
compounds presenting a catechol moiety, have shown to be more potent than those lacking this unit. The same behaviour was observed in the present study and the tested 2,3-diarylxanthones presented similar effects on the $\mathrm{NO}$ scavenging activity to those presented by the structural similar compounds. Other authors also reported that some flavonoids were good "NO scavengers. ${ }^{39}$ Thus, considering the structural similarity between the above-referred compounds, it is very likely that the studied hydroxyxanthones might present some therapeutic value.

Concerning $\mathrm{ONOO}^{-}$, all the studied hydroxy-2,3-diarylxanthones were able to scavenge this RNS in a very efficient way. Apparently, the scavenging effect is related to the number and position of the hydroxyl substituents on the D and E-rings. However, these features have a different contribution when the assays are performed in the absence or in the presence of $\mathrm{NaHCO}_{3}$. Figure 6 describes the $\mathrm{ONOO}^{-}$scavenging activity of the catecholic-2,3diarylxanthones, in the absence of bicarbonate. We can observe that by increasing the number of hydroxyl substituents, higher is the scavenging effect of these compounds. Derivatives $\mathbf{2 c}, \mathbf{3 b}$ and $\mathbf{3 c}$ were visibly more active than the compounds $\mathbf{1 c}$ and $\mathbf{3 a}$, which possesses only two hydroxyl groups. Heijnen et al. ${ }^{40}$ studied the $\mathrm{ONOO}^{-}$scavenging of substituted phenols and several flavonoids and concluded that the activity is positively influenced by the number of $\mathrm{OH}$ groups and by the presence of catechol units in the above-referred molecules. When we performed this assay in the presence of bicarbonate the results seemed to be dependent on the position of the ortho-dihydroxyl moiety, which were sometimes favourable and others unfavourable to the scavenging activity, depending on the concentration of the antioxidant species (Fig. 7). The reaction between $\mathrm{ONOO}^{-}$and $\mathrm{CO}_{2}$ is very fast $\left(K=3-5.8 \times 10^{4} \mathrm{M}^{-1} \mathrm{~s}^{-1}\right)^{41,42}$ and results in the formation of the nitrosoperoxycarbonate anion $\left(\mathrm{ONOOCO}_{2}^{-}\right)$, whose decomposition leads to the formation of different species including the highly reactive $\mathrm{NO}_{2}$ and $\mathrm{CO}_{3}{ }^{-}$- radicals. ${ }^{43}$ Thus, the observed variation in the scavenging activities is probably due to the different ability to scavenge the resulting radicals.

In conclusion, the results obtained in the present study revealed new promising 2,3-diarylxanthones with outstanding ROS and RNS scavenging properties. In fact, some of the studied derivatives proved to be extremely efficient scavengers, showing, in some cases, $\mathrm{IC}_{50}$ values under $1 \mu \mathrm{M}$. The results obtained are largely affected by the number and position of hydroxyl groups in the xanthone core. The ROO scavenging activity seems to depend mostly on the presence of phenolic groups while for the other tested ROS and RNS, xanthones with a catechol ring were the most potent scavengers. These findings allowed the establishment of structure-activity relationships and that 2,3-diarylxanthones can have a promising future as antioxidant pharmacophores.

\section{Materials and methods}

\subsection{Chemicals}

All the chemicals and reagents were of analytical grade. Ascorbic acid, DAF-2, dihydrolipoic acid, DHR, ebselen, 30\% hydrogen peroxide, lucigenin, $\beta$-nicotinamide adenine dinucleotide (NADH), nitroblue tetrazolium chloride (NBT), 3-(aminopropyl)-1-hydroxy-3-isopropyl-2-oxo-1-triazene (NOC-5), penicillamine, phenazine methosulfate (PMS), sodium hypochlorite solution, with $4 \%$ available chlorine, rutin and tiron were obtained from Sigma-Aldrich (St. Louis, USA). $\alpha, \alpha^{\prime}$-Azodiisobutyramidine dihydrochloride (AAPH), histidine, and trolox were obtained from Fluka Chemie $\mathrm{GmbH}$ (Steinheim, Germany). Fluorescein sodium salt and quercetin were obtained from Aldrich (Milwaukee, USA). All the other reagents were obtained from Merck (Darmstadt, Germany).

The polyhydroxy-2,3-diarylxanthones $\mathbf{1 a - 3 c}$ were synthesized according to procedures previously described in the literature ${ }^{10}$ and showed to possess identical spectroscopic and analytical data. ${ }^{8-10}$ Briefly, 2,3-diarylxanthones 1-3 have been obtained by a five steps chemical sequence starting from simple starting materials (Scheme 1). ${ }^{10}$ The first step of this synthesis involves the esterification of 2'-hydroxyacetophenone 4 with cinnamoyl chloride derivatives $\mathbf{5 a - c}$ (5a is commercial and $\mathbf{5 b}, \mathbf{c}$ are prepared in situ from the corresponding cinnamic acids and phosphorous oxychloride in dry pyridine). Baker-Venkataraman rearrangement of esters $\mathbf{6 a}-\mathbf{c}$ with potassium hydroxide in DMSO afforded $\beta$-diketones 7a-c; these were brominated and cyclodehydrated by treatment with PTT (phenyltrimethylammonium tribromide), leading to the synthesis of 2-bromo-2-styrylchromones 8a-c. The Heck reaction of bromochromones $\mathbf{8 a - c}$ with styrene derivatives $\mathbf{9 a - c}$

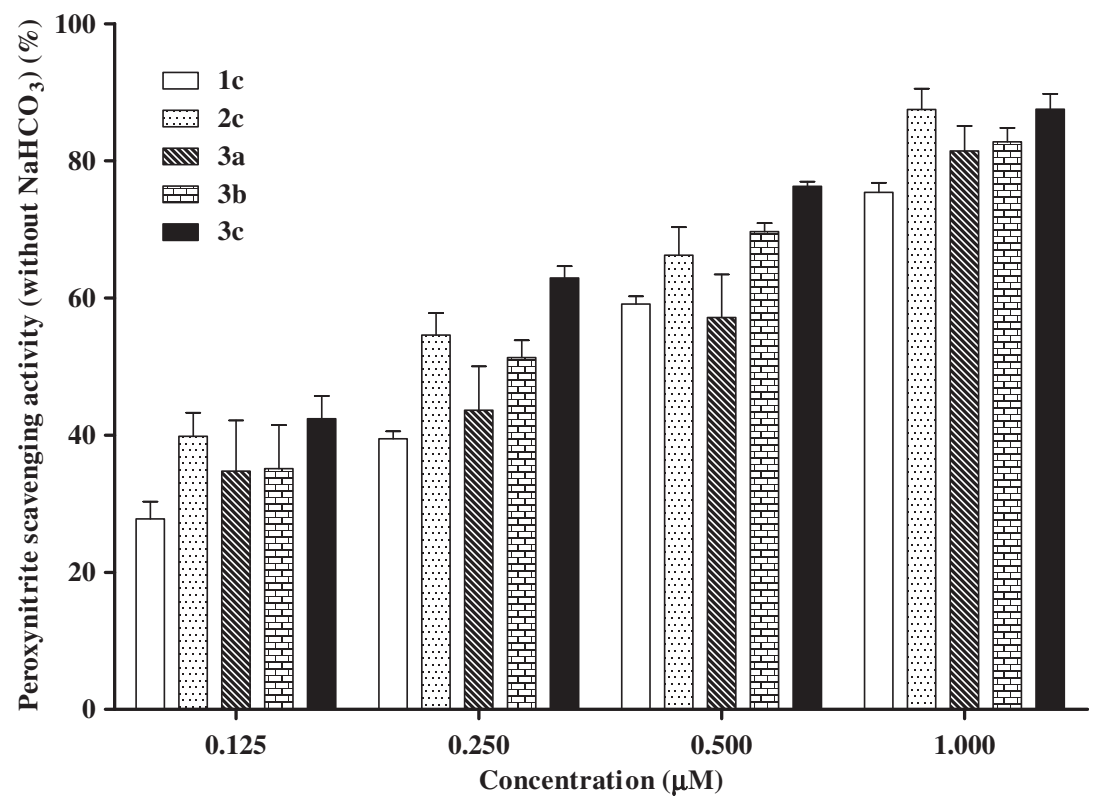

Figure 6. $\mathrm{ONOO}^{-}$scavenging activity of 2,3-diarylxanthones 1c, 2c, 3a-c. Each column represents the values obtained from five experiments, performed in triplicate (mean \pm SEM). 


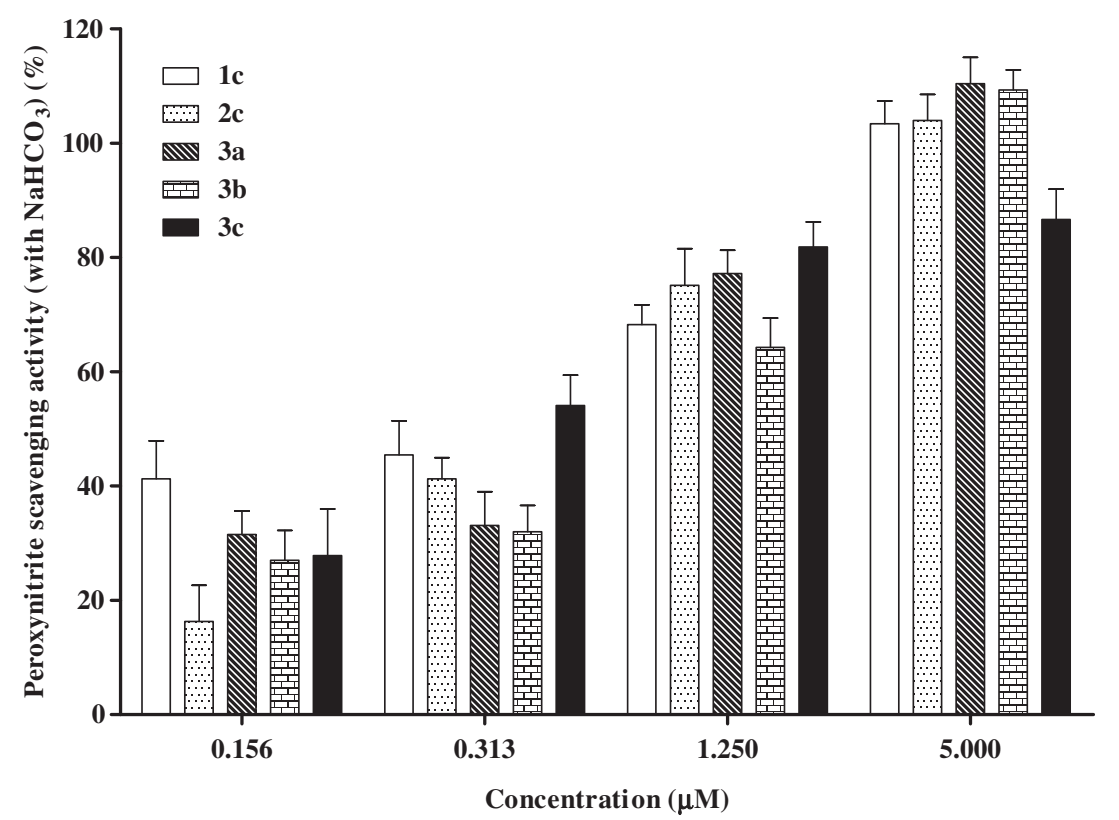

Figure 7. $\mathrm{ONOO}^{-}$scavenging activity of 2,3-diarylxanthones $\mathbf{1 c}, \mathbf{2 c}$, $\mathbf{3 a}-\mathbf{c}$, in the presence of $\mathrm{NaHCO}_{3} 25 \mathrm{mM}$. Each column represents the values obtained from five experiments, performed in triplicate (mean \pm SEM).

yielded 2,3-diarylxanthones 10a-c, 11a-c and 12a-c. The final step of our synthetic route consisted on the demethylation of these methoxy-2,3-diarylxanthones 10a-c, 11a-c and 12a-c by treatment them with boron tribromide ( 2.5 equiv per methyl group) in dichloromethane.

\subsection{Equipment}

A microplate reader (Synergy HT, BIO-TEK), with spectrophotometric, fluorimetric, and chemiluminometric detection, plus temperature control capacity, was used for all ROS and RNS scavenging assays.

\subsection{ROS and RNS scavenging assays}

\subsubsection{Superoxide radical scavenging assay}

The $\mathrm{O}_{2}{ }^{--}$was generated by the NADH/PMS system and the $\mathrm{O}_{2} \cdot$ scavenging activity was determined by monitoring the $\mathrm{O}_{2}{ }^{-}$-induced reduction of NBT, according to a previously developed procedure. $^{38}$ The effect of the tested compounds dissolved in DMSO was determined spectrophotometrically at $560 \mathrm{~nm}$ during $2 \mathrm{~min}$. The antioxidant tiron was used as positive control. The results were expressed as the percentage inhibition of the NBT reduction to diformazan. Each assay corresponds to five experiments, conducted in triplicate.

\subsubsection{Hydrogen peroxide scavenging assay}

The $\mathrm{H}_{2} \mathrm{O}_{2}$ scavenging activity was measured using a previously described chemiluminescence methodology based on the $\mathrm{H}_{2} \mathrm{O}_{2}$-induced oxidation of lucigenin. ${ }^{38}$ The tested compounds were dissolved in DMSO and the chemiluminescence assays were performed at $37^{\circ} \mathrm{C}$. The endogenous antioxidant ascorbic acid was used as positive control. The results were expressed as the percentage inhibition of the $\mathrm{H}_{2} \mathrm{O}_{2}$-induced oxidation of lucigenin. Each assay corresponds to five experiments, conducted in triplicate.

\subsubsection{Hypochlorous acid scavenging assay}

The $\mathrm{HOCl}$ was measured by monitoring the $\mathrm{HOCl}$-induced oxidation of DHR to rhodamine 123 . The fluorimetric assays were per- formed at $37^{\circ} \mathrm{C}$ and the tested compounds were dissolved in ethanol, as previously described. ${ }^{38} \mathrm{HOCl}$ was daily prepared by adjusting the $\mathrm{pH}$ of a $1 \%$ solution of $\mathrm{NaOCl}$ to 6.2 with dropwise addition of $10 \% \mathrm{H}_{2} \mathrm{SO}_{4}$. Lipoic acid was used as positive control. The results were expressed as the percentage inhibition of $\mathrm{HOCl}-$ induced oxidation of DHR. Each assay corresponds to five experiments, conducted in triplicate.

\subsubsection{Singlet oxygen scavenging assay}

The ${ }^{1} \mathrm{O}_{2}$ was generated by the thermal decomposition of a previously synthesized water-soluble endoperoxide [disodium 3,3'-(1,4-naphthalene)bispropionate $\left.\left(\mathrm{NDPO}_{2}\right)\right] \cdot{ }^{44}$ The ${ }^{1} \mathrm{O}_{2}$ scavenging activity was measured by monitoring the oxidation of nonfluorescent DHR to fluorescent rhodamine 123 , at $37^{\circ} \mathrm{C}$, after a 30 min incubation period, as described in the literature. ${ }^{44}$ Ascorbic acid was used as positive control. The results were expressed as the percentage inhibition of ${ }^{1} \mathrm{O}_{2}$-induced oxidation of DHR. Each assay corresponds to five experiments, conducted in triplicate.

\subsubsection{Peroxyl radical scavenging assay}

The ROO* scavenging activity was measured by monitoring the fluorescence decay resulting from ROO-induced oxidation of fluorescein and expressed as the 'oxygen radical absorbance capacity' (ORAC), according to a described procedure. ${ }^{38}$ ROO' was generated by thermal decomposition of AAPH and the tested compounds dissolved in acetone and subsequently diluted in phosphate buffer (mixture 1:9). Trolox was used as the standard control in each study. Ascorbic acid was used as positive control. The results were expressed as ORAC values. Each assay corresponds to four experiments, conducted in triplicate.

\subsubsection{Nitric oxide scavenging assay}

The NO scavenging activity was measured by monitoring the -NO-induced oxidation of non-fluorescent DAF-2 to the fluorescent triazolofluorescein (DAF-2T), using a previously described method. $^{38}$ 'NO was generated by NOC-5, the tested compounds dissolved in DMSO and the fluorimetric signal was detected after a 30 min incubation period, at $37{ }^{\circ} \mathrm{C}$. Rutin was used as positive control. The results were expressed as the percentage inhibition of 


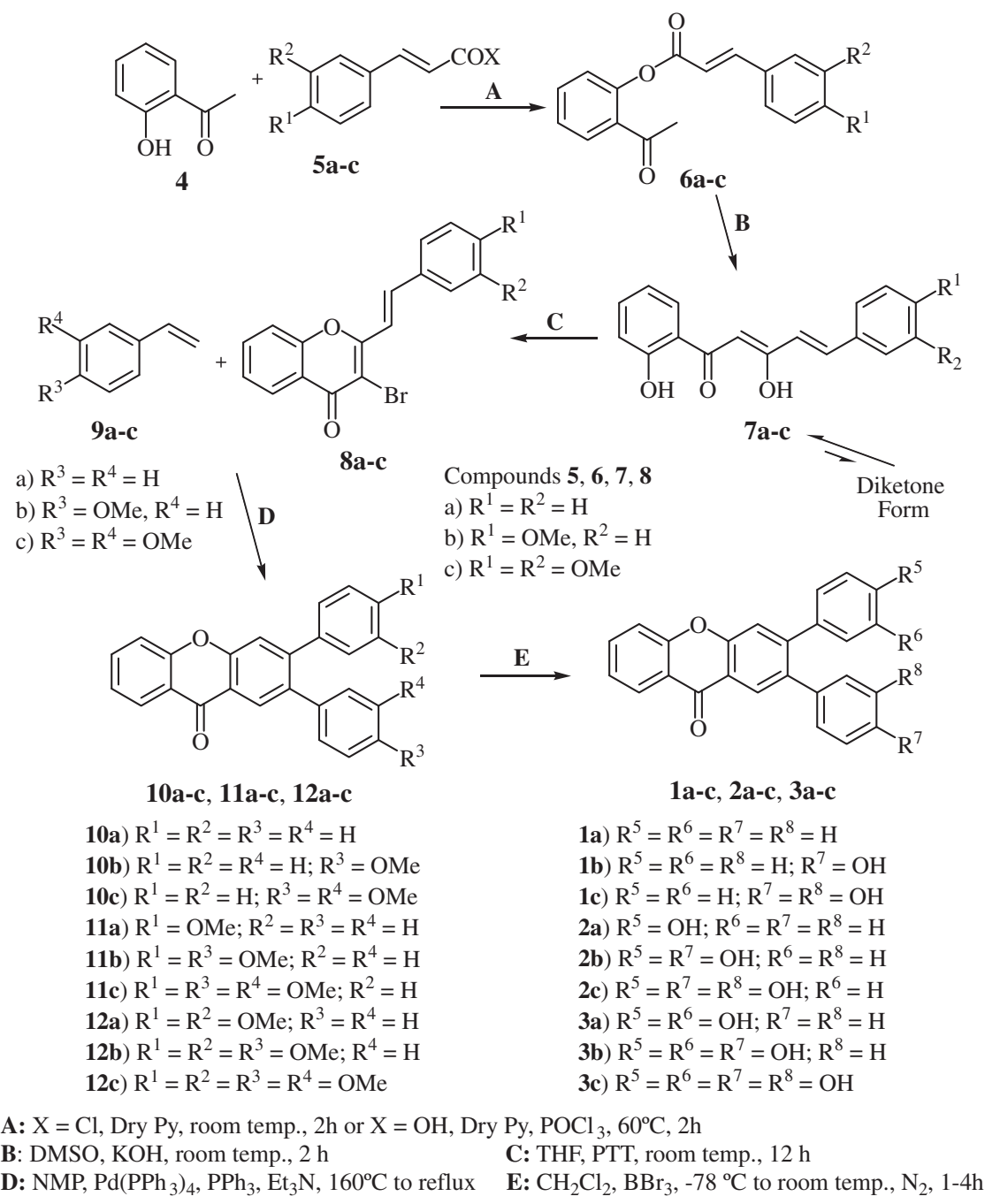

Scheme 1.

-NO-induced oxidation of DAF-2. Each assay corresponds to five experiments, conducted in triplicate.

\subsubsection{Peroxynitrite scavenging assay}

The $\mathrm{ONOO}^{-}$scavenging activity was measured by monitoring the $\mathrm{ONOO}^{-}$-induced oxidation of non-fluorescent DHR to fluorescent rhodamine 123 , as previously described. ${ }^{38} \mathrm{ONOO}^{-}$was synthesized as reported in the literature by some of the authors. ${ }^{45}$ The assays were performed at $37^{\circ} \mathrm{C}$, the tested compounds dissolved in DMSO and the fluorimetric signal detected after a 2 min incubation period. Ebselen was used as positive control. In a parallel set of experiments, the assays were performed in the presence of $25 \mathrm{mM} \mathrm{NaHCO}$ in order to simulate the physiological $\mathrm{CO}_{2}$ concentrations in vivo. This evaluation is important because, under physiological conditions, the reaction between $\mathrm{ONOO}^{-}$and bicarbonate is predominant, with a very fast rate constant $\left(k_{2}=3-5.8 \times 10^{4} \mathrm{M}^{-1} \mathrm{~s}^{-1}\right) .{ }^{46}$ The results were expressed as the percentage inhibition of $\mathrm{ONOO}^{-}$-induced oxidation of DHR. Each assay corresponds to five experiments, conducted in triplicate.

\section{Acknowledgements}

Sincere thanks are expressed to Faculdade de Farmácia da Universidade do Porto, and also to Universidade de Aveiro, Fundação para a Ciência e a Tecnologia (Portugal) and FEDER for funding the Organic Chemistry Research Unit. M.F. and A.G. acknowledge Fundação para a Ciência e a Tecnologia (FCT) and Fundo Social Europeu (FSE) their Ph.D. (SFRH/BD/28502/2006) and post-doctoral (SFRH/BPD/63179/2009) Grant, respectively.

\section{References and notes}

1. Hostettman, K.; Hostettman, M. Methods in Plant Biochemistry. In Plant Phenolics; Dey, P. M., Harbone, J. B., Eds.; Academic Press, 1989; Vol. 1, p 493.

2. Roberts, J. C. Chem. Rev. 1961, 38, 591.

3. Gales, L.; Damas, A. M. Curr. Med. Chem. 2005, 12, 2499.

4. Bennett, G. J.; Lee, H.-H. Phytochemistry 1989, 28, 967.

5. Vieira, L. M. M.; Kijjoa, A. Curr. Med. Chem. 2005, 12, 2413.

6. Fukawa, I.; Yoneda, H.; Asahi, K. K. K. K. European Patent EP0237004, Sep, 1987.

7. Kelkar, A. S.; Letcher, R. M.; Cheung, K.-K.; Chiu, K.-F.; Brown, G. D. J. Chem. Soc., Perkin Trans. 1 2000, 3732.

8. Santos, C. M. M.: Silva, A. M. S.; Cavaleiro, J. A. S. Synlett 2005, 3095.

9. Santos, C. M. M.; Silva, A. M. S.; Cavaleiro, J. A. S. Synlett 2007, 3113.

10. Santos, C. M. M.; Silva, A. M. S.; Cavaleiro, J. A. S. Eur. J. Org. Chem. 2009, 2642.

11. Pinto, M. M. M.; Sousa, M. E.; Nascimento, M. S. J. Curr. Med. Chem. 2005, 12, 2517.

12. Finnegan, R. A.; Stephani, G. M.; Ganguli, G.; Bhattacharya, S. K. J. Pharm. Sci. 1968, 57, 1039.

13. Da Re, P.; Sagramora, L.; Mancini, V.; Valenti, P.; Cima, L. J. Med. Chem. 1970, 13, 527.

14. Rivera, D. G.; Balmaseda, I. H.; León, A. A.; Hernández, B. C.; Montiel, L. M. Garrido, G. G.; Cuzzocrea, S.; Hernández, R. D. J. Pharm. Pharmacol. 2006, 58, 385.

15. Dube, M.; Zunker, K.; Neidhart, S.; Carle, R.; Steinhart, H.; Paschke, A. J. Agric. Food Chem. 2004, 52, 3938 
16. Marona, H.; Szkaradek, N.; Karczewska, E.; Trojanowska, D.; Budak, A.; Bober, P. Przepiórka, W. Cegla, M. Szneler. E. Arch Pharm Chem Life Sci. 2009, 342, 9.

17. Abdel-Lateff, A.; Klemke, C.; König, G. M.; Wright, A. D. J. Nat. Prod. 2003, 66, 706.

18. Park, H. H.; Park, Y.-D.; Han, J.-M.; Im, K.-R.; Lee, B. W.; Jeong, I. Y.; Jeong, T.-S.; Lee, W. S. Bioorg. Med. Chem. Lett. 2006, 16, 5580.

19. Chung, M. I.; Weng, J. R.; Wang, J. P.; Teng, C. M.; Lin, C. N. Planta Med. 2002, 68 25.

20. Riscoe, M.; Kelly, J. X.; Winter, R. Curr. Med. Chem. 2005, 12, 2539.

21. Portela, C.; Afonso, C. M. M.; Pinto, M. M. M.; Ramos, M. J. Bioorg. Med. Chem. 2004, 12, 3313.

22. Ee, G. C. L.; Daud, S.; Izzaddin, S. A.; Rahmani, M. J. Asian Nat. Prod. Res. 2008, 10, 475.

23. Zhang, H.-Z.; Kasibhatla, S.; Wang, Y.; Herich, J.; Guastella, J.; Tseng, B.; Drewe J.; Cai, S. X. Bioog. Med. Chem. 2004, 12, 309.

24. Fernandes, E. R.; Carvalho, F. D.; Remião, F. G.; Bastos, M. L.; Pinto, M. M. Gottlieb, O. R. Pharm. Res. 1995, 12, 1756.

25. Gnerre, C.; Thull, U.; Gaillard, P.; Carrupt, P. A.; Testa, B.; Fernandes, E.; Silva, F.; Pinto, M.; Pinto, M. M. M.; Wolfender, J. L.; Hostettmann, K.; Cruciani, G. Helv. Chim. Acta 2001, 84, 552

26. Khan, M. T. H.; Orhan, I.; Senol, F. S.; Kartal, M.; Sener, B.; Dvorská, M.; Šmejkal, K.; Šlapetová, T. Chem. Biol. Interact. 2009, 181, 383.

27. Chen, C. H.; Lin, J. Y.; Lin, C. N.; Hsu, S. Y. J. Nat. Prod. 1992, 55, 691.

28. Pothitirat, W.; Chomnawang, M. T.; Supabphol, R.; Gritsanapan, W. Fitoterapia 2009, 80, 442.

29. Jiang, D.-J.; Dai, Z.; Li, Y.-J. Cardiovasc. Drug Rev. 2004, 22, 91.

30. Sun, D.; Zhang, S.; Wei, Y.; Yin, L. Acta Biochim. Biophys. Sin. 2009, 1033.
31. Yu, L.; Zhao, M.; Yang, B.; Zhao, Q.; Jiang, Y. Food Chem. 2007, 104, 176.

32. Lee, B. W: Lee, J. H. Lee, S.-T; Lee, H. S.; Lee, W. S.; Jeong, T.-S.; Park, K. H. Bioorg. Med. Chem. Lett. 2005, 5, 5548.

33. Pedraza-Chaverrí, J.; Reyes-Fermín, L. M.; Nolasco-Amaya, E. G.; Orozco-Ibarra, M.; Medina-Campos, O. N.; González-Cuahutencos, O.; Rivero-Cruz, I.; Mata, R. Exp. Toxicol. Pathol. 2009, 61, 491.

34. Pietta, P.-G. J. Nat. Prod. 2000, 63, 1035.

35. Cao, G.; Sofic, E.; Prior, R. L. Free Radical Biol. Med. 1997, 22, 749

36. Chimi, H.; Cillard, J.; Cillard, P.; Rahmani, M. J. Am. Oil Chem. Soc. 1991, 68, 307.

37. Gomes, A.; Neuwirth, O.; Freitas, M.; Couto, D.; Ribeiro, D.; Figueiredo, A. G. P. R.; Silva, A. M. S.; Seixas, R. S. G. R.; Pinto, D. C. G. A.; Tomé, A. C.; Cavaleiro, J. A. S.; Fernandes, E.; Lima, J. L. F. C. Bioorg. Med. Chem. 2009, 17, 7218

38. Gomes, A.; Fernandes, E.; Silva, A. M. S.; Santos, C. M. M.; Pinto, D. C. G. A.; Cavaleiro, J. A. S.; Lima, J. L. F. C. Bioorg. Med. Chem. 2007, 15, 6027.

39. van Acker, S. A.; Tromp, M. N.; Haenen, G. R.; van der Vijgh, W. J.; Bast, A Biochem. Biophys. Res. Commun. 1995, 214, 755.

40. Heijnen, C. G. M.; Haenen, G. R. M. M.; Vekemans, J. A. J. M.; Bast, A. Environ. Toxicol. Pharmacol. 2001, 10, 199.

41. Radi, R.; Cosgrove, T. P.; Beckman, J. S.; Freeman, B. A. Biochem. J. 1993, 290, 51

42. Denicola, A.; Freeman, B. A.; Trujillo, M.; Radi, R. Arch. Biochem. Biophys. 1996 333, 49.

43. Squadrito, G. L.; Pryor, W. A. Free Radical Biol. Med. 1998, 25, 392.

44. Costa, D.; Fernandes, E.; Santos, J. L. M.; Pinto, D. C. G. A.; Silva, A. M. S.; Lima, J. L. F. C. Anal. Bioanal. Chem. 2007, 387, 2071

45. Fernandes, E.; Gomes, A.; Costa, D.; Lima, J. L. F. C. Life Sci. 2005, 77, 1983.

46. Whiteman, M.; Ketsawatsakul, U.; Halliwell, B. Ann. N.Y. Acad. Sci. 2002, 962, 242 